\title{
Nanoflow LC/IMS-MS \\ and LC/IMS-CID/MS of Protein Mixtures
}

\author{
Renã A. Sowell, Stormy L. Koeniger, Stephen J. Valentine, \\ Myeong Hee Moon, ${ }^{*}$ and David E. Clemmer \\ Department of Chemistry, Indiana University, Bloomington, Indiana, USA
}

\begin{abstract}
A simple ion trap/ion mobility/time-of-flight (TOF) mass spectrometer has been coupled with nanoflow liquid chromatography to examine the feasibility of analyzing mixtures of intact proteins. In this approach proteins are separated using reversed-phase chromatography. As components elute from the column, they are electrosprayed into the gas phase and separated again in a drift tube prior to being dispersed and analyzed in a TOF mass spectrometer. The mobilities of ions through a buffer gas depend upon their collision cross sections and charge states; separation based on these gas-phase parameters provides a new means of simplifying mass spectra and characterizing mixtures. Additionally it is possible to induce dissociation at the exit of the drift tube and examine the fragmentation patterns of specific protein ion charge states and conformations. The approach is demonstrated by examining a simple threecomponent mixture containing ubiquitin, cytochrome $c$, and myoglobin and several larger prepared protein mixtures. The potential of this approach for use in proteomic applications is considered. (J Am Soc Mass Spectrom 2004, 15, 1341-1353) @ 2004 American Society for Mass Spectrometry
\end{abstract}

I n the last few years, mass spectrometry (MS) techniques have emerged as a means of analyzing complex protein mixtures, such as those encountered in the emerging field of proteomics [1-6]. Perhaps the most widely-used approach involves separation of proteins using two-dimensional (2D) gel electrophoresis (GE). In this approach, proteins are separated based on differences in their molecular weight and isoelectric focusing point [7-10], and ultimately can be displayed as spots on a $2 \mathrm{D}$ gel. In an ideal case, a single spot contains a single protein, which can be excised, enzymatically digested, and analyzed by MS. The mass-tocharge $(\mathrm{m} / \mathrm{z})$ ratios of ions that are detected (often called a peptide map) can be used to identify the protein. The detection of all of the peptides from a protein can yield detailed information about the complete sequence, and may provide insight about locations of any post-translational modifications that are present. In practice, the analysis of proteins by this approach is more complex. It is often the case that several proteins migrate to the same 2D-GE spot; thus, individual proteins are identified only when it is possible to interpret multiple overlaying peptide maps. Additionally, it is rare for data from this approach to contain peaks corresponding to peptides that span the entire sequence. Differences in

\footnotetext{
Published online August 6, 2004

Address reprint requests to David E. Clemmer, Department of Chemistry, Indiana University, Bloomington, IN 47405, USA. E-mail: clemmer@ indiana.edu

*Current address: Department of Chemistry, Yonsei University, Seoul, South Korea
}

the physical and chemical properties of the peptides (e.g., solubility or ionization efficiency) can lead to discrimination against significant fractions of the protein sequence. Although it is often possible to identify a protein from a partial map, one cannot guarantee the complete protein sequence when some regions are missing.

With these ideas in mind, a number of groups are developing methods to examine proteins directly [1116]. A particularly useful approach is to couple liquid chromatography (LC) techniques with MS methods that can generate fragments of the whole protein (the topdown approach) $[17,18]$. This can be done by collecting protein fractions separated by multidimensional separation techniques and then analyzing individual fractions with MS -an off-line strategy [17-19]. These approaches have the advantage that large quantities of purified samples can be obtained; additionally it is possible to examine individual fractions for extended periods and utilize ion activation techniques to induce dissociation in order to define detailed information about sequences and any modifications that are present [20]. A disadvantage of this type of strategy is that it is time consuming.

Another approach is to couple the separation approach directly to the mass spectrometer -an on-line strategy [11]. This allows many samples to be rapidly examined; however, several issues, which limit the amount of detailed information obtained for an eluting component, arise - especially when fragmentation studies are desired. For example, electrospray ionization 


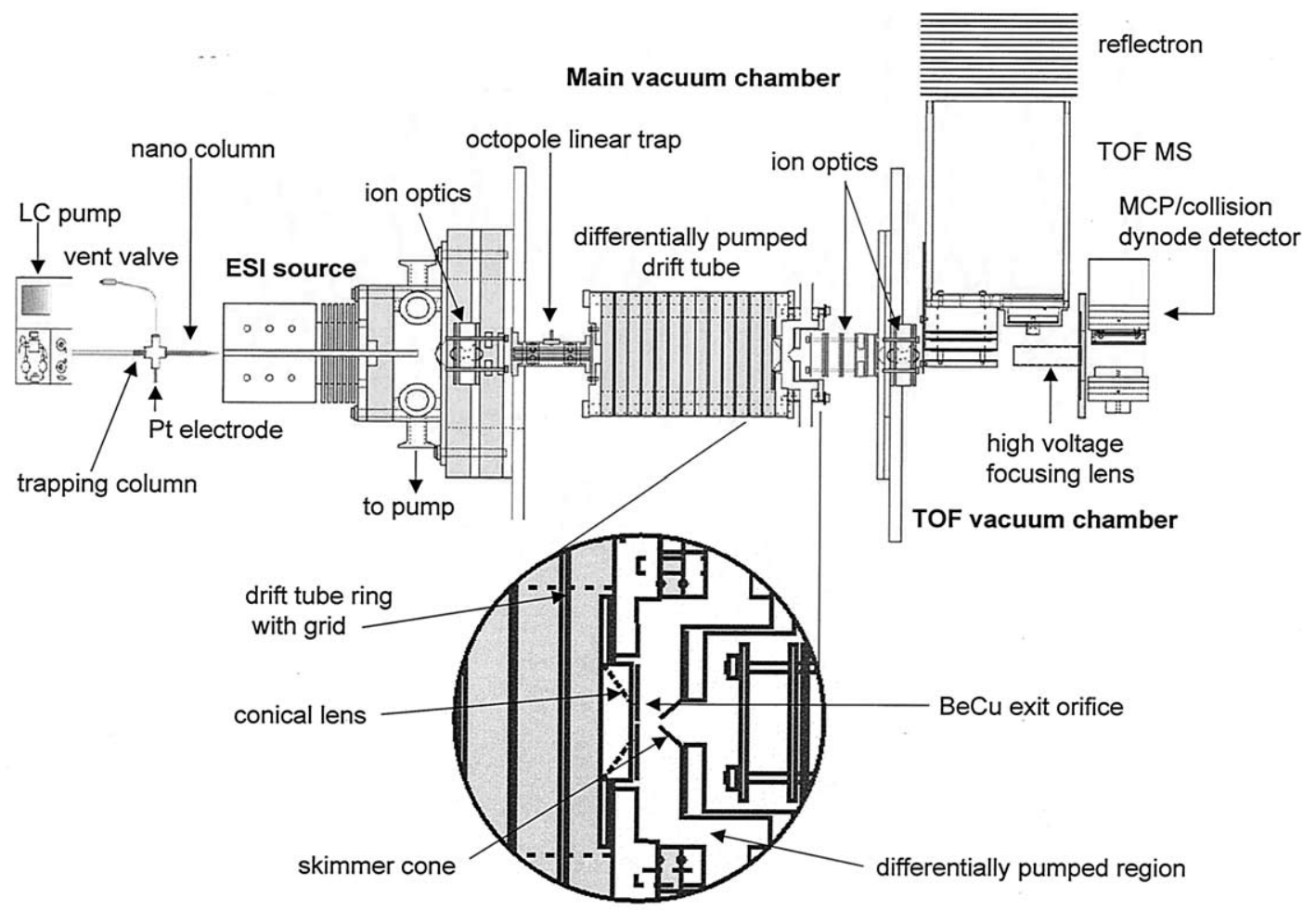

Figure 1. A schematic diagram of the nanoflow LC apparatus coupled to the split-field drift tube instrument. In the insert is a blowup of the split-field region at the back of the drift tube. This split-field region is described in detail in the text.

(ESI) usually produces multiple charge states. Because fragment patterns from different charge states are often complementary for obtaining high-levels of sequence coverage and the positions of modifications, it is desirable to mass-select and fragment many charge states $[21,22]$. However, in practice it is often not possible to select, activate, and detect fragments from multiple charge states when experiments are carried out on-line because components may be present for analysis for only fractions of a minute.

In this paper we describe the development of a new approach for the analysis of intact protein mixtures involving nanoflow LC coupled to an ion mobility spectrometry (IMS) separation. The mobility of an ion depends upon the ratio of its collision cross section and charge state [23-25]. We (and others) have previously shown that it is possible to separate different protein ion conformations and charge states based on differences in mobilities [26-35]. Here, we describe this approach for a mixture of proteins that is separated by LC prior to introduction into the drift tube. After the combined LC/IMS separation we determine $\mathrm{m} / \mathrm{z}$ values for parent ions by dispersing ions again into a time-offlight (TOF) mass spectrometer. In addition, it is possible to collisionally activate the ions at the exit of the drift tube - generating distinct fragment patterns for the distribution of charge states. From these data it is often possible to distinguish the fragment patterns for individual charge states. We demonstrate the approach by describing recent results that have been obtained for several prepared mixtures of commercially available proteins, ranging in complexity from three to ten proteins.

\section{Experimental}

\section{General}

The present experiment utilizes a combination of techniques: nanoflow LC combined with ESI; ion trapping and IMS separations; as well as collision induced dissociation (CID) and TOF MS. Reviews of IMS methods are given elsewhere [25,33-36] and the overall approach associated with IMS-TOF measurements has been described [37-40]. A schematic diagram of the instrument that was used in these studies is shown in Figure 1. Briefly, experiments are carried out as follows. A mixture of proteins is introduced onto a capillary column (described below) and separated by reversed-phase LC. As components elute from the column they are electrosprayed into the entrance of a hybrid IMS-TOF instrument and are focused into a cylindrically-symmetric, linear octopole ion trap. Here, the continuous beam is accumulated for $\sim 5.5 \mathrm{~ms}$ and the accumulated ions are ejected as concentrated ( $\sim 30$ to $100 \mu \mathrm{s})$ packets into a $21.90 \mathrm{~cm}$ long split-field drift tube (described in detail below) that is filled with a mixture of $\sim 1.20$ Torr of He and 0.10 Torr of Ar buffer gasses. In the first region of 
the drift tube, ions drift through the buffer gasses under the influence of a weak-applied electric field $(\sim 5$ $\left.\mathrm{V} \cdot \mathrm{cm}^{-1}\right)$; different conformations and charge states that are present in the initial packet separate because of differences in their mobilities through the gas. Ions leave the first region of the drift tube through a nickel mesh grid and enter a shorter drift region where either low- or high-field focusing can be applied. Under low-field focusing conditions in the second field region of the drift tube, intact precursor ions are focused through the exit orifice; under high-field conditions, the precursors can be collisionally activated and may fragment. In the latter case, fragmentation occurs on a timescale that is much shorter than residence times of ions in the first field region of the drift tube. Therefore, it is possible to correlate fragments with precursor ions because they have the same total drift times, as described previously [39]. Upon exiting the drift tube, precursor ions (or precursors and fragments) are focused into the source region of a reflectron geometry TOF mass spectrometer and dispersed again according to differences in $\mathrm{m} / \mathrm{z}$ ratios. The acquisition and analysis of combined IMS-TOF data are described in more detail below.

\section{Preparation of protein mixtures}

Proteins [cytochrome $c$ (horse, 95\%), ubiquitin (bovine, $90 \%$ ), myoglobin (horse, 90\%), ribonuclease A (bovine, $85 \%), \alpha$-lactalbumin (bovine, 85\%), hemoglobin (bovine), carbonic anhydrase (bovine, 100\%), lactoferrin (bovine, $90 \%$ ), catalase (bovine), $\alpha$-casein (bovine, $85 \%$ ), $\beta$-casein (bovine, 90\%), and rhodanese (bovine)] were purchased from Sigma and used without further purification. Stock solutions of $0.25 \mathrm{mg} \cdot \mathrm{mL}^{-1}$ (aqueous with $0.1 \%$ formic acid) of each protein were prepared and used in a range of combinations to generate mixtures of varying complexity and protein concentration. The specific combinations that are shown below include: a three protein mixture of ubiquitin, cytochrome $c$ and myoglobin, which was studied over total protein concentrations ranging from 15 to $150 \mathrm{ng} \cdot \mu \mathrm{L}^{-1}$ (5 to 50 $\mathrm{ng} \cdot \mu \mathrm{L}^{-1}$ of each protein); several protein mixtures that were studied over a range of equimolar conditions in which the total protein consumed was either 75 or 150 ng.

\section{Nanoflow LC}

Fused silica nanocolumns $(75 \mu \mathrm{m} \times 75 \mathrm{~mm}$, Polymicro Technology LLC, Phoenix, AZ) with a pulled tip were packed in-house with a methanol or acetone slurry of 5 $\mu \mathrm{m}, 300 \AA$ A Magic C4 reversed-phase material (Microm BioResourses Inc., Auburn, CA). Column packing was performed under a constant pressure of He (1000 psi) allowing a self-assembled frit to be formed near the end of the tip. A trapping column of $100 \mu \mathrm{m}$ inner diameter with an integral frit (New Objective Inc.,Woburn, MA) was also packed in-house with a slurry of Magic C4 material $(5 \mu \mathrm{m}, 300 \AA)$ to a length of $1.5 \mathrm{~cm}$. A $1.0 \mu \mathrm{L}$ volume of the protein mixture was injected onto the column. A PEEK microcross was utilized for the trapping column and nanocolumn connections as shown in Figure 1. A binary gradient was delivered by an Ultimate pump (Dionex, Sunnyvale, CA) and mobile phases consisted of $3 \%$ acetonitrile in water (A), and acetonitrile (B) each containing $0.1 \%$ formic acid. Protein mixtures were separated at a flow rate of 250 $\mathrm{nL} \cdot \min ^{-1}$ using similar linear gradient conditions: 15 min. at $0 \%$ B, $10 \%$ B in 2 min., an increase to $80 \%$ B over $60 \mathrm{~min}$. (or $30 \mathrm{~min}$. for the three protein mixture), and held at $80 \%$ B for a period of $10 \mathrm{~min}$.

\section{Nested ion mobility/time-of-flight measurements}

The timescales of the experiments in this study are such that hundreds of time-of-flight spectra are recorded for single drift time distributions of ions. We refer to this as a "nested" technique because flight times are recorded on $\mu$ s timescales, within individual drift time windows across the ms timescale of the mobility separation; this has been described previously [37,39]. In addition, LC separations in this study occur on the order of seconds to minutes. Thus, the acquisition of drift(flight) time measurements is also carried out in a nested fashion, within the individual time windows associated with the LC separation. The standard nomenclature that we use to describe LC/IMS-MS datasets is as follows: retention times $\left(t_{\mathrm{R}}\right)$, drift times $\left(t_{\mathrm{D}}\right)$, and flight times $\left(t_{\mathrm{F}}\right)$ denoted as values of $t_{\mathrm{R}}\left[t_{\mathrm{D}}\left(t_{F}\right)\right]$ and given in units of $\min [\mathrm{ms}(\mu \mathrm{s})]$. Flight times are subsequently converted to $\mathrm{m} / \mathrm{z}$ values utilizing a standard multipoint external calibration or internal calibration of a known protein in the sample. Also, retention times may be described as frame numbers, which correspond to the positions of peak maxima in the reversed-phase separation. LC data was acquired by recording $t_{\mathrm{D}}\left(t_{\mathrm{F}}\right)$ datasets in $\sim 10 \mathrm{~s}$ increments. Data acquisition began after an initial 25-minute delay.

\section{A split-field drift tube for ion separation and collisional activation}

We have recently described a split-field drift tube that allows parent ions to be separated and dissociated prior to analysis in the TOF mass spectrometer (see the insert in Figure 1) [40]. Figure 2 shows a detailed schematic of the interface between the first and second field regions of the drift tube. At the exit of the drift tube, ions are subjected to a weak focusing field that can be tuned to induce fragmentation of protein ions. This field is created by applying voltages to three electrodes near the exit of the drift tube: the last drift tube lens with grid ( $90 \%$ transmittance, Ni) of the first field region of the drift tube; an inverted stainless steel conical lens; and, the exit orifice plate that is constructed of BeCu. Overall, these electrodes are designed to create a balloonshaped field for focusing the diffuse ion cloud through 


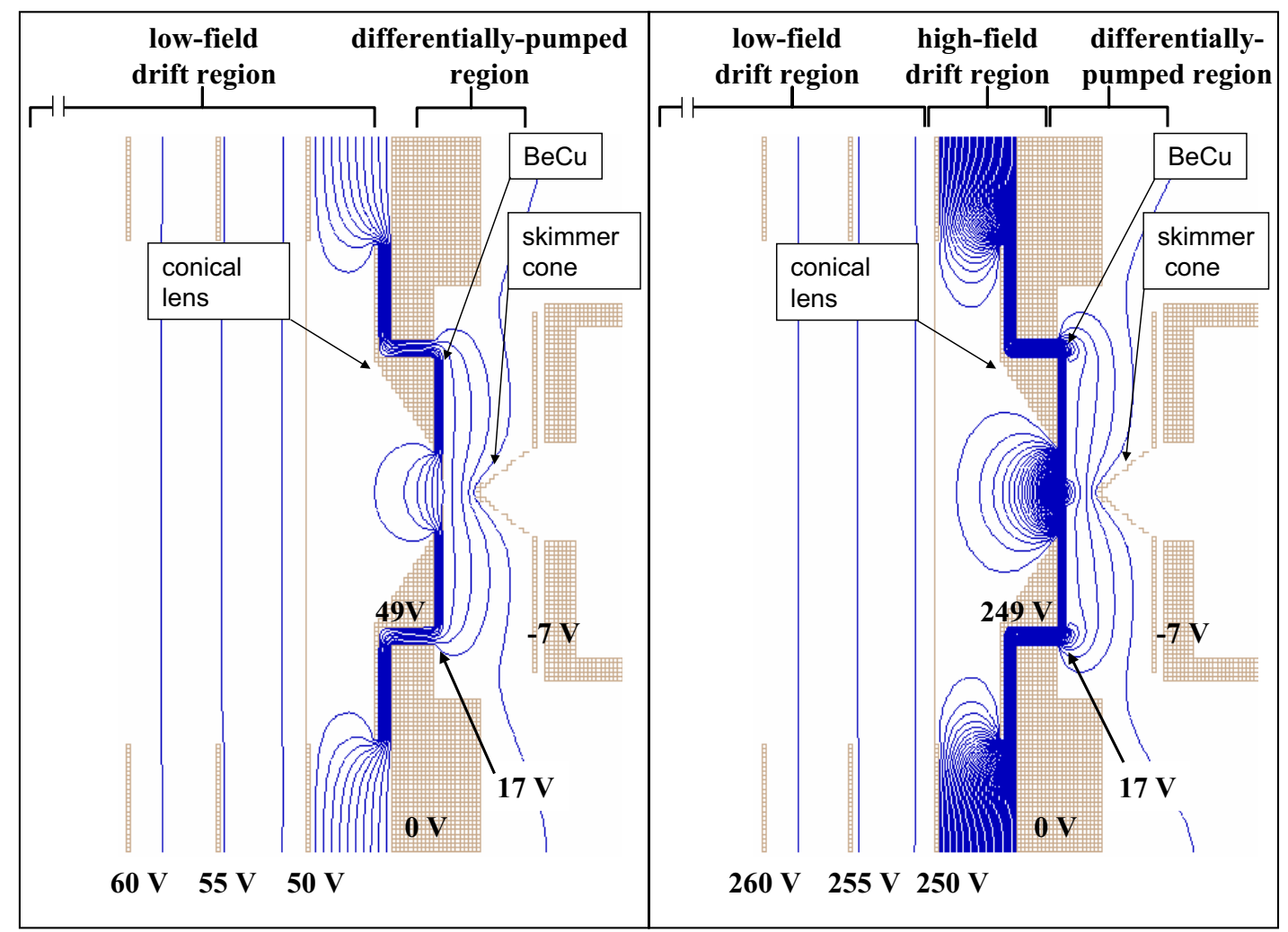

Figure 2. Schematic diagram of electrode geometries and applied voltages associated with the second field region of the current instrument. The solid lines correspond to equipotential lines created by modeling the system using the SIMION program [42]. The equipotential lines for parent ion spectra under low-field conditions are shown on the left. The balloon-shaped field is useful for focusing ions through the drift tube exit orifice [40]. To the right are the equipotential lines for fragment ion spectra obtained under high-field conditions. The lines show the $5 \mathrm{~V}$ contour increments in both low- and high-field conditions.

the $\mathrm{BeCu}$ exit hole [41]; at high-fields, the region also can be used to induce dissociation [40]. Also shown in Figure 2 are two example plots of the equipotential lines (obtained from modeling the system of electrodes using the SIMION program) [42] for the exit region of the drift tube that represents typical conditions that we have employed in these studies. These conditions are nominally those that we refer to as low- and high-field conditions. The low-field potential lines that are shown are created by a voltage drop of $32 \mathrm{~V}$ between the grid/conical lenses and the $\mathrm{BeCu}$ exit plate; these conditions favor transmission of precursor ions. Highfield conditions (which favor formation of fragment ions) are created by a voltage drop of $232 \mathrm{~V}$ between the grid/conical lenses and the $\mathrm{BeCu}$ exit plate (this region will hereafter be referred to as the grid/conical lens assembly). Precursor and fragment ions are then pulsed into an orthogonal geometry reflectron time-of-flight mass spectrometer where flight times are recorded.

\section{Injection of ions from the octopole trap into the drift tube}

As mentioned above, the continuous beam of electrosprayed ions is accumulated in the octopole trap and subsequently injected into the drift tube. An important experimental parameter is the injection energy. As ions enter the drift tube their kinetic energies become thermalized by collisions with the buffer gas. This results in a transient heating/cooling cycle that can induce structural changes in the ions [25]. We (and others) have previously studied this process in some detail and most of the systems that have been examined here (as mixtures) have been studied individually $[25,28,35,36,43]$. Generally, for proteins, low-charge states favor compact conformations (having collision cross sections that are near values calculated from native structures found in solution); high-charge states usually adopt more extended conformations, structures that are favored due to a decrease in the Coulomb repulsion between protonated sites [29,44-48]. Intermediate charge states display interesting behavior that is often difficult to predict. The overall mobilities of these ions depend heavily upon electrospray and source conditions that are used prior to introduction in the drift tube $[49,50]$.

We note also that in some systems ion conformations appear to change during the time that they are stored in the trap [28]. Here we have used the octopole to accumulate the continuous ion beam; thus, those ions are stored continuously for time periods as long as 5.5 
ms, the repetition time of the experiment. A range of experimental injection voltages was employed (from 60 $\mathrm{V}$ to $136 \mathrm{~V}$ ). Below we show results that were obtained using 90 and $136 \mathrm{~V}$.

\section{Results and Discussion}

\section{Nanoflow LC/IMS-MS of a three protein mixture: understanding the influence of concentration and injection voltage on the appearance of datasets}

The nanoflow LC/IMS-TOF configuration that is described here was developed about eighteen months ago and has since been used to study a number of systems. During this time we varied many of the experimental parameters and have noticed several that influence the positions and appearances of peaks. Here, we briefly summarize important effects.

As expected, the chromatographic separation is influenced by the choice of LC method (stationary phase, mobile phase compositions and gradients) as well column preparation and temperature control (we have not carefully controlled the temperature in these studies). Two additional factors routinely influence the appearance of the data: the analyte concentration; and the voltage used to inject ions into the drift tube. These effects are summarized in the data that are shown in Figures 3 and 4 , which show several example $t_{\mathrm{R}}\left[t_{\mathrm{D}}\right]$ plots as well as examples of individual $t_{\mathrm{D}}\left(t_{\mathrm{F}}\right)$ frames, respectively. The first effect has to do with the concentration of proteins used. Consider the $t_{\mathrm{R}}\left[t_{\mathrm{D}}\right]$ plots (Figure $3 \mathrm{a}$ and $3 \mathrm{~b}$ ) obtained upon injecting two different total protein concentrations (150 $\mathrm{ng} \cdot \mu \mathrm{L}^{-1}$ and 15 $\mathrm{ng} \cdot \mu \mathrm{L}^{-1}$, respectively) of a simple three component protein mixture (ubiquitin, cytochrome $c$ and myoglobin) onto the LC column. These results are obtained upon injecting ions into the drift tube using relatively low-injection voltages -a process that favors the formation of compact conformations as reported previously $[25,36,51]$. At the higher concentration of $150 \mathrm{ng} \cdot \mu \mathrm{L}^{-1}$ three broad features centered at $t_{\mathrm{R}}\left[t_{\mathrm{D}}\right]$ values of 42.8[2.80], 44.3[2.84] and 52.2[2.92] are observed. An interesting aspect of features such as these (which are often obtained at relatively low injection energies and relatively high concentrations) is the appearance of flat topped peaks; in some cases the peak center shows a depression (a dipped top peak, i.e., a dip in the region of the peak that we have previously found as the peak maximum). The origin of this appearance is associated with detector saturation and is discussed in more detail below.

Upon injecting a total protein concentration of 15 $\mathrm{ng} \cdot \mu \mathrm{L}^{-1}$ (5 $\mathrm{ng} \cdot \mu \mathrm{L}^{-1}$ of each protein), the appearance of the datasets is quite different. The first and second analytes that elute display distinct peaks that are separated based on differences in their mobilities. The positions of these peaks are $t_{\mathrm{R}}\left[t_{\mathrm{D}}\right]=45.2[2.30,2.43,2.67$, 2.92 , and 3.04], as well as $t_{\mathrm{R}}\left[t_{\mathrm{D}}\right]=46.2[2.26,2.39,2.63$, 2.84 , and 3.08]. The third analyte still appears as a broad feature. Upon detailed inspection, we find dipped top peaks centered at $t_{\mathrm{R}}\left[t_{\mathrm{D}}\right]=52.7[2.51,2.71$, and 2.84]. In the first two peaks, individual features are resolved based on differences in their mobilities because it is possible to observe the high intensity portions of the peaks. The different features that are resolved correspond to different charge states and conformations of the protein.

The second parameter that influences the appearance of these data is the injection voltage. Several groups have studied the mobilities of ubiquitin, cytochrome $c$ and myoglobin $[25,28-36,43,45,47,52,53]$. All three of these proteins exhibit distinctive structural transitions upon energizing collisions. One of the effects that we observe is that peak positions and intensities across the mobility dimension can vary. Figure $3 c$ shows $t_{R}\left[t_{\mathrm{D}}\right]$ values for the high concentration ubiquitin, cytochrome $c$, and myoglobin mixture ( $50 \mathrm{ng} \cdot \mu \mathrm{L}^{-1}$ of each protein) upon injecting ions into the drift tube with an injection voltage (IV) of $136 \mathrm{~V}$. Under these conditions, the distribution shifts to span a wide range of $t_{\mathrm{D}}$ values. For example, the first peak (having values of $t_{\mathrm{D}} \sim 2.2 \mathrm{~ms}$ to $3.4 \mathrm{~ms}$ in the $90 \mathrm{~V}$ injection data) is observed from 1.9 to $4.2 \mathrm{~ms}$ upon injection at $136 \mathrm{~V}$. In this case, the new peaks that are observed at longer drift times correspond to ions that must have adopted more extended geometries upon injection into the drift tube. All three of the features that are observed display this behavior. We note that sharp peak shapes are observed, even though the concentration of the proteins that were injected ( 50 $\mathrm{ng} \cdot \mu \mathrm{L}^{-1}$ ) is the same as that used to record the dipped top features obtained at low injection voltages. In this case, as discussed in more detail below, the greater dispersion of ions (IV $=136 \mathrm{~V})$ across the mobility dimension spreads the total signal out (relative to the low IV $=90$ data set) and thus effects of detector saturation are decreased.

So far, we have described the appearance of these data without assigning the features to specific proteins. Clearly one potential advantage of the inclusion of a mobility dimension is that mobilities (and cross sections) can be used to identify and assign proteins. In the present dataset, peak assignments are done by examining individual $t_{\mathrm{D}}\left(t_{\mathrm{F}}\right)$ frames. Nested drift(flight) time distributions for peaks (in Figure $3 \mathrm{c}$ ) at $t_{\mathrm{R}}=37.2 \mathrm{~min}$., $t_{\mathrm{R}}=38.0 \mathrm{~min}$., and $t_{\mathrm{R}}=41.7 \mathrm{~min}$. are shown in Figure 4 . The observed charge states produced by ESI correspond to the $[\mathrm{M}+6 \mathrm{H}]^{6+}$ to $[\mathrm{M}+21 \mathrm{H}]^{21+}$ of cytochrome c, the $[\mathrm{M}+4 \mathrm{H}]^{4+}$ to $[\mathrm{M}+13 \mathrm{H}]^{13+}$ of ubiquitin and the $[\mathrm{M}+8 \mathrm{H}]^{8+}$ to $[\mathrm{M}+27 \mathrm{H}]^{27+}$ of myoglobin, respectively, as indicated in the figure. We note also that all of these systems show evidence for several types of conformations that have been observed previously [28,43,49,52]. We anticipate that in some cases, information about mobilities may aid in defining the protein structure in solution. For example, variations in disulfide bonding has been shown to influence gas-phase structure [54]. 
a)

retention time (min.)

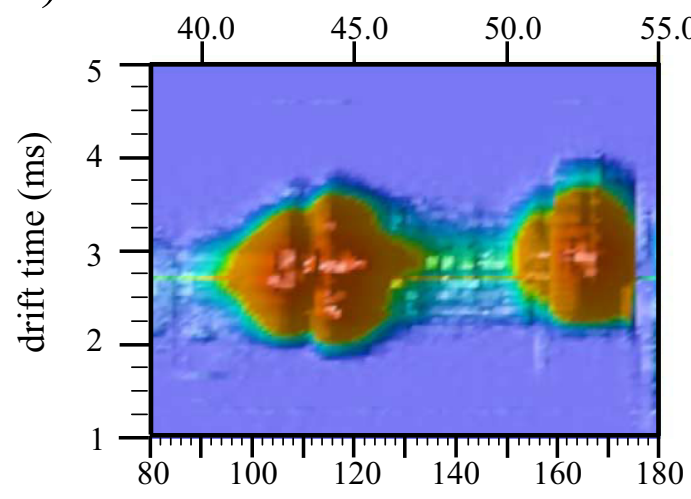

retention time (min.)

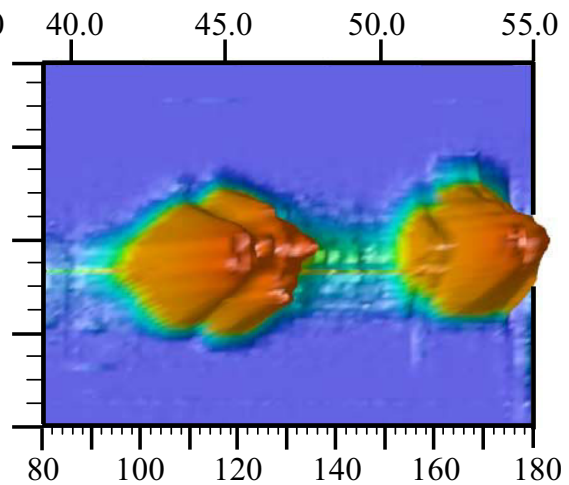

b)
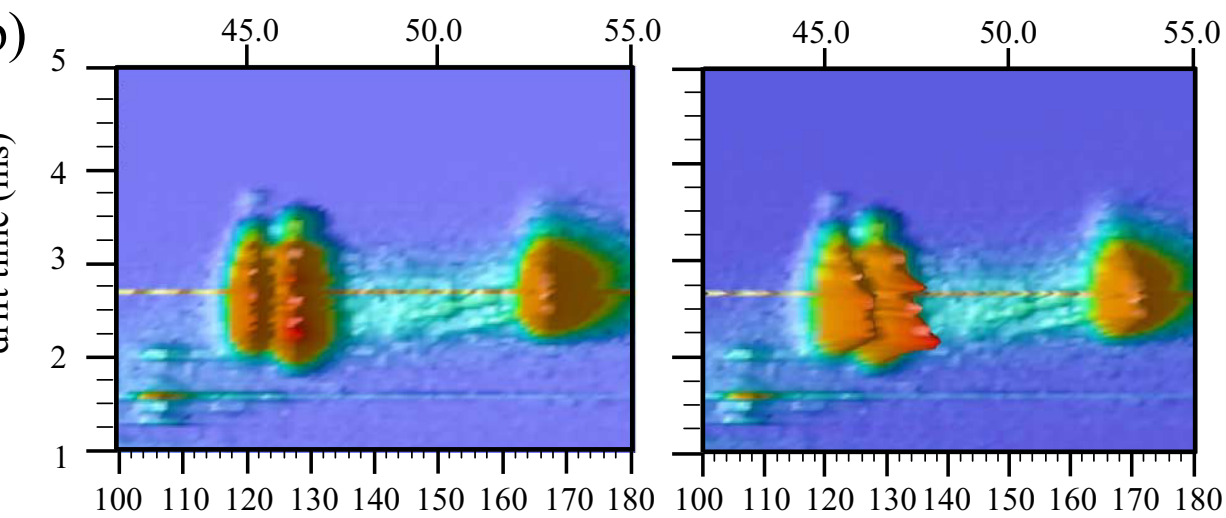

c)
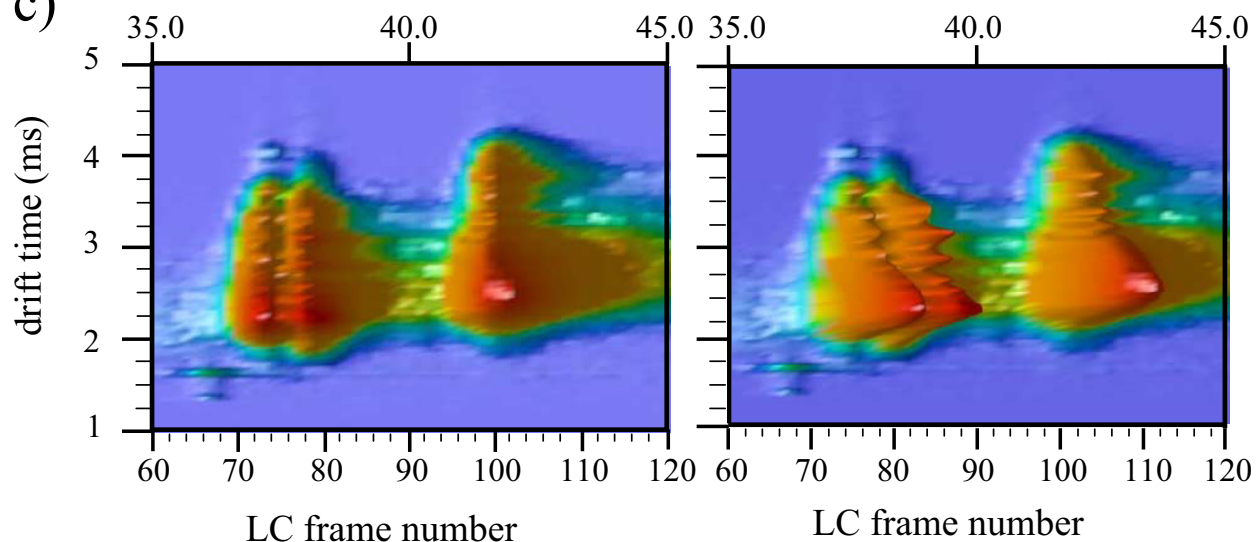

Figure 3. (a) shows a two-dimensional retention (drift) time $\left(t_{\mathrm{R}}\left[t_{\mathrm{D}}\right]\right)$ contour plot for a protein mixture of ubiquitin, cytochrome $c$, and myoglobin with a total concentration of $150 \mathrm{ng} \cdot \mu \mathrm{L}^{-1}$. Protein ions were injected into the drift tube with an injection energy of $90 \mathrm{~V}$. (b) is a similar $t_{\mathrm{R}}\left[t_{\mathrm{D}}\right]$ data for this mixture at a total protein concentration of $15 \mathrm{ng} \cdot \mu \mathrm{L}^{-1}$ and an injection energy of $136 \mathrm{~V}$. Contour plots were generated using an in-house script developed in the OpenDX software, version 4.2.0 (www.opendx.org). The view of the plots on the left is a front, orthographic view; the plots on the right are either orthographic or perspective plots rotated at an angle between $5^{\circ}-20^{\circ}$. The plots in (a)-(c) are not plotted on the same intensity scale. Intensities are plotted on a false color scale such that the most intense features are displayed in red and the least intense features are in blue.

\section{Differences associated with detection of ions} in LC-TOF and LC/IMS-TOF experiments

In order to understand the trends that are observed for different concentrations and injection voltages, it is useful to briefly discuss the differences in ion detection for the LC/IMS-TOF and LC-TOF experiments. Con- sider, for example, an LC-TOF experiment in which one component elutes from the column and upon ESI generates a continuous on-axis ion beam with an intensity of $10^{7}$ ions $\cdot \mathrm{s}^{-1}$. In this case, during the time that this analyte elutes from the column ( $\sim 30$ to $120 \mathrm{~s}$ in our experiments), the average time between ions entering 


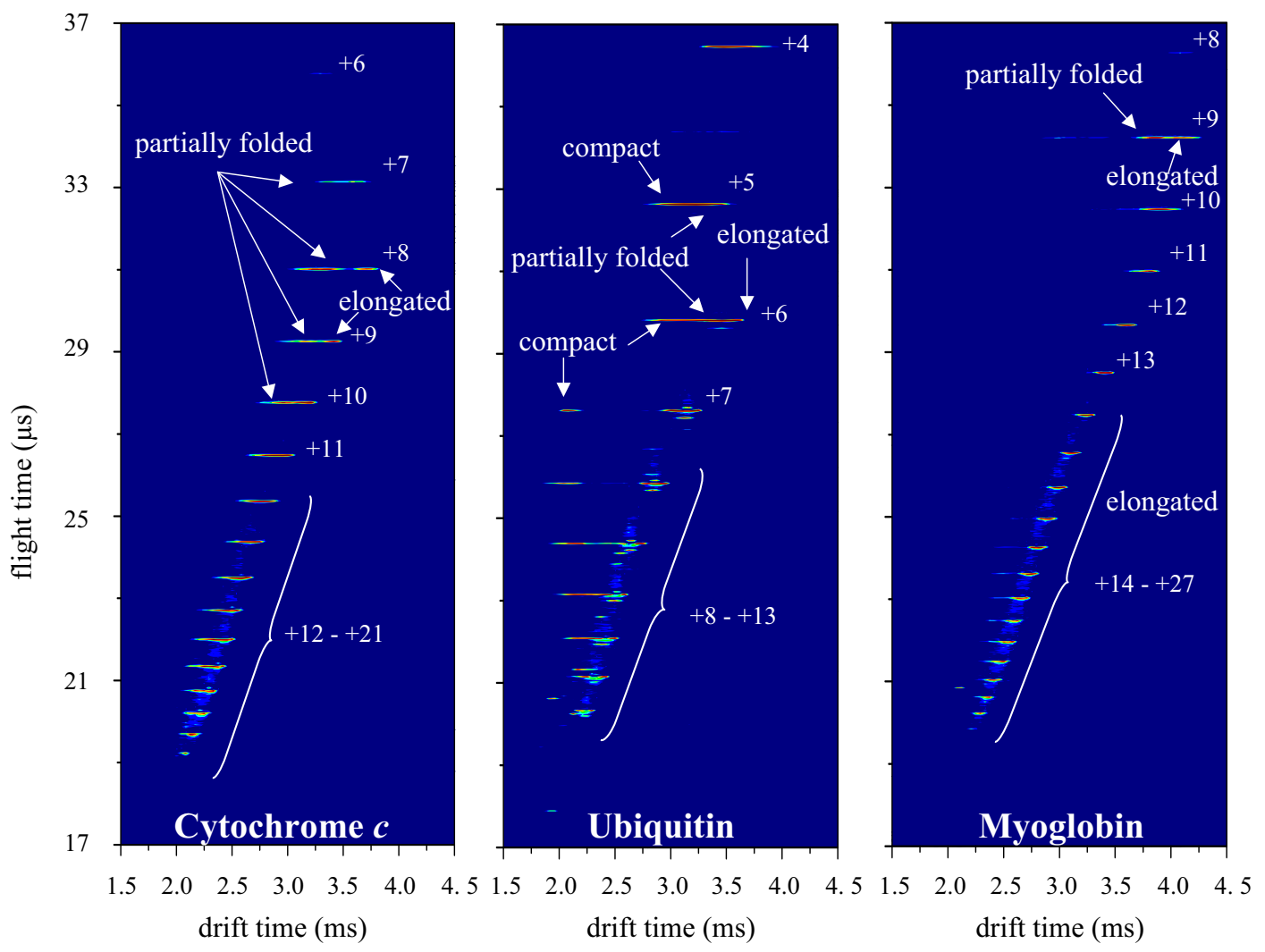

Figure 4. Nested drift(flight) time distributions are shown for cytochrome $c t_{\mathrm{R}}=37.2 \mathrm{~min}$. (frame number 73), ubiquitin $t_{\mathrm{R}}=38.0 \mathrm{~min}$ (frame number 78) and myoglobin $t_{\mathrm{R}}=41.7 \mathrm{~min}$ (frame number 100), respectively. Observed charges states are the $[\mathrm{M}+6 \mathrm{H}]^{6+}$ to $[\mathrm{M}+21 \mathrm{H}]^{21+}$ for cytochrome $c$, the $[\mathrm{M}+4 \mathrm{H}]^{4+}$ to $[\mathrm{M}+13 \mathrm{H}]^{13+}$ for ubiquitin and the $[\mathrm{M}+8 \mathrm{H}]^{8+}$ to $[\mathrm{M}+27 \mathrm{H}]^{27+}$ for myoglobin, respectively. The types of structures observed, compact, partially folded, and elongated for different charge states are also labeled in these plots.

the TOF source would be $0.1 \mu$ s. If the source region of the TOF instrument is pulsed at a rate of $3 \times 10^{4} \mathrm{~Hz}$ (i.e., every $33 \mu \mathrm{s}$ ) and the TOF ion detection efficiency is $1 \%$ (i.e., the fraction of the total beam that strikes the TOF detector -in our case a microchannel plate/anode assembly), then it is necessary to detect and digitize three events for each TOF source pulse. This is feasible with commercially available detectors and time-to-digital converters.

Now consider the same analyte as it elutes in the LC/IMS-TOF experiment. The IMS separation is initiated by accumulating the continuous ion beam in the octopole trap, and then injecting concentrated packets of ions into the drift tube. Accumulation of a $10^{7}$ ions $\cdot \mathrm{s}^{-1}$ beam for $10 \mathrm{~ms}$ (a typical experimental repetition rate) would lead to a packet of $10^{5}$ ions for mobility experiments. Ion packets (ejected from the trap) are typically $\sim 100 \mu \mathrm{s}$ in duration. If only one analyte structure is favored as a mobility-dispersed packet that enters the TOF source region, then we expect to observe a single, intense and narrow peak. Under the experimental conditions employed, the full width at half maximum (FWHM) of a single conformer type would typically be on the order of $\sim 100 \mu \mathrm{s}$. In this case, the most concentrated region of the packet of ions would be accessible in the TOF source region for only about 3 TOF pulses (assuming a TOF repetition rate of $3 \times 10^{4} \mathrm{~Hz}$-or, three $33 \mu$ s drift windows under the high intensity region of the $100 \mu$ sWHM of the peak). A TOF detector efficiency of $1 \%$ would require that we digitize $\sim 68 \%$ of $\sim 1000$ ions within three TOF source pulses (or $\sim 226$ ions per TOF pulse). In this case, the ion detection efficiency is low because most ions also have nearly identical flight times in the TOF mass spectrometer.

The net result of these considerations is that under some conditions during the separation the density of ions in the source region of the TOF instrument in LC/IMS-TOF experiments is much greater than the density of ions from the same overall ion signal in an analogous LC-TOF experiment. Experimentally, we observe that abundant analytes generate peaks that have characteristic shapes -large features with flat tops (and sometimes dipped top peaks) that indicate that our detection system has been saturated. ${ }^{*}$ This is the case for the data that we have obtained upon injection of 50

*The flat top shape arises because our system can count no more events. At higher signal intensities, dipped top peaks arise because of a recovery time associated with the detector. 
$\mathrm{ng} \cdot \mu \mathrm{L}^{-1}$ of each of the three proteins at low injection voltages. Under the low injection voltage conditions, ions favor a distribution of structures and charge states having nearly the same mobilities. Thus, they arrive into the TOF source region over a narrow time frame (e.g., in the case of cytochrome $c \sim 2.2$ to $3.4 \mathrm{~ms}$ ). Under these conditions, the detector cannot keep up with the intense ion beam. One solution to the saturation issue is to decrease the sample concentration. It appears that at a concentration of $5 \mathrm{ng} \cdot \mu \mathrm{L}^{-1}$ detector saturation is negligible. Additionally, at high injection voltages it is possible to change the conformations of ions. This spreads the intense portion of the beam over a wider range of drift times. This allows more TOF experiments to be employed for detection and also reduces saturation.

\section{Demonstration of high-field LC/IMS-CID/MS for a simple protein mixture.}

A unique feature of the IMS/TOF instrument described here is that the drift field is split into two sections: a low-field section that allows ions to be separated based on differences in their mobilities; and, a high-field section that is employed to collisionally activate ions for the production of fragments. Effectively, this allows mobility-separated ions to be subject to energizing collisions immediately before they exit the drift tube. The high-field portion of the drift tube has a much shorter length than the low-field region; thus, any fragment ions that are produced in the high-field region have drift times that are nearly identical to drift times associated with the parent ions (obtained when the second-field region is operated at low voltages). The coincidence in drift times with the anteceding precursor ions and fragment ions that are formed in the high-field allows a mixture of ions to be subjected to dissociation without $m / z$ selection. In this case, precursor ions and fragments that are formed are grouped together according to their drift times to yield the CID/MS datasets.

A number of experiments have employed both highand low-field configurations. Figure 5 shows a single nested $t_{\mathrm{D}}\left(t_{\mathrm{F}}\right)$ frame that is obtained from a typical nanoflow high-field LC/IMS-CID/MS experiment in which the simple cytochrome $c$, ubiquitin, and myoglobin mixture, described above was injected onto the column. From studies obtained under precursor ion conditions (i.e., operation of the second-field region as a low-field focusing element) we observe the charge state distribution associated with electrosprayed ubiquitin ions ( +4 to +13 are often observed). When the second field region is modulated to high-field conditions (i.e., the grid/conical lens assembly voltages are increased by $200 \mathrm{~V}$ compared with low-field conditions) we produce the $t_{\mathrm{D}}\left(t_{\mathrm{F}}\right)$ frame shown in Figure 5 . Under these conditions, we observe families of ions that are coincident in drift time. For example, at $\sim 3.0 \mathrm{~ms}$, we observe an intense series of peaks that extends over a flight time

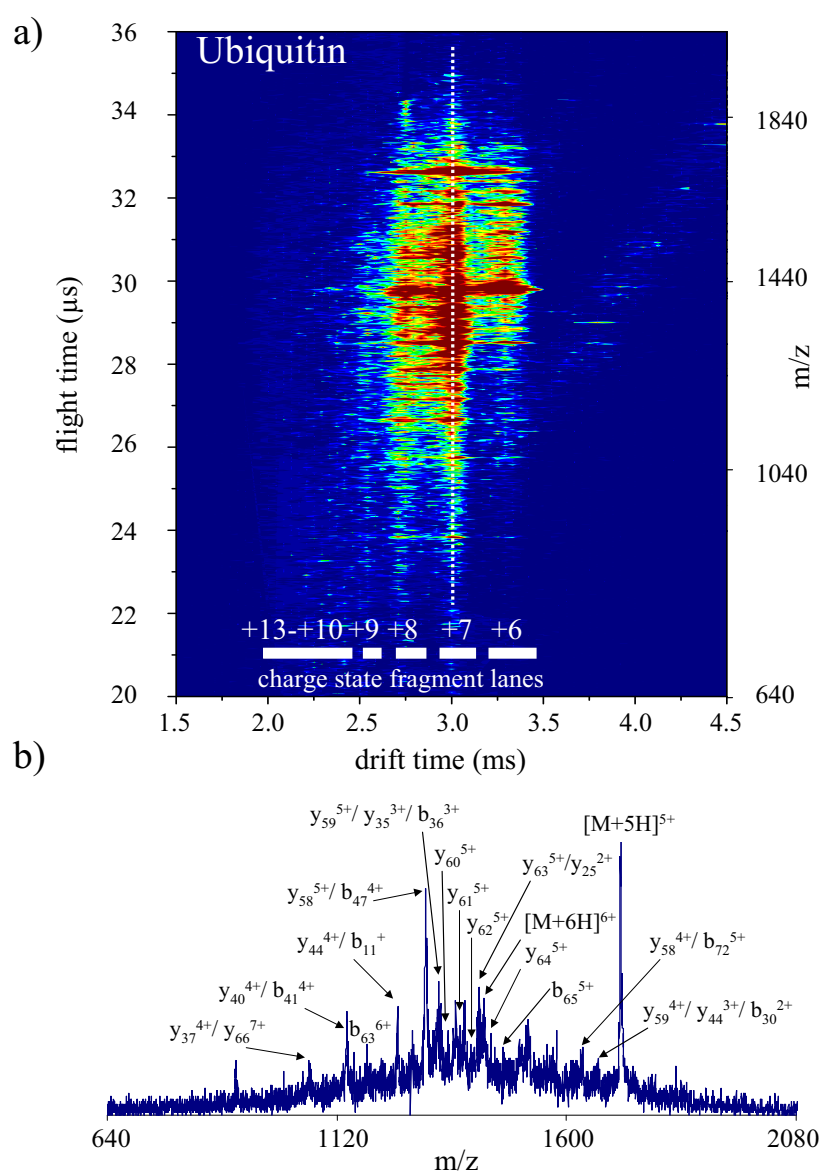

Figure 5. (a) shows nested drift(flight) time distributions of the fragmentation patterns for ubiquitin. These data are obtained by integrating the peak centered at $t_{\mathrm{R}}=58 \mathrm{~min}$ and flight times have been converted to $m / z$ values on the right axis for simplicity. Charge state "fragment lanes" for the $[\mathrm{M}+6 \mathrm{H}]^{6+}$ to $[\mathrm{M}+13 \mathrm{H}]^{13+}$ charge states are labeled in the plot. In (b) is an MS/MS spectrum integrated at $t_{\mathrm{D}}=2.96 \mathrm{~ms}$ corresponding to the fragmentation patterns observed for the $[\mathrm{M}+7 \mathrm{H}]^{7+}$ charge state of ubiquitin.

range of $\sim 22$ to $36 \mu \mathrm{s}$. A slice through this family of peaks at $3.0 \mathrm{~ms}$ which shows the intensity of the many features that are observed is also shown in Figure 5. As the second field region is decreased, this series of peaks begins to decrease in intensity and also shifts to slightly longer times; under our lowest field conditions (i.e., analogous to those shown in Figure 4), we observe that the drift time of the parent ion is at $3.1 \mathrm{~ms}$ and that the $\mathrm{m} / \mathrm{z}$ ratio of this ion is 1224.4 , indicating that this is the $[\mathrm{M}+7 \mathrm{H}]^{7+}$ charge state. With this information, it is possible to tentatively assign many of the peaks in the CID/MS spectrum obtained at $3.0 \mathrm{~ms}$ to fragment ions that are expected to be formed upon dissociation of ubiquitin [21,27]. These assignments are shown in Figure 5 .

As mentioned above a unique aspect of this approach is that information about other charge state fragmentation patterns is also obtained. For example, a slice across the dataset at slightly longer drift times, $\sim 3.4 \mathrm{~ms}$ provides a CID/MS spectrum for the +6 
charge state. At slightly shorter drift times we observe evidence for the +8 and +9 charge state dissociation patterns and a very weak (and broad band) associated with fragmentation of the +10 to +13 charge states. We refer to these streaks across the dataset as charge state fragment lanes because they have some similarities in appearance with the lanes that are used to obtain information about sequence in one-dimensional gel techniques [55].

In some proteins (for example myoglobin, see Figure 4 ), charge states are sufficiently resolved based on differences in mobilities and it is possible to extract CID/MS spectra for fragmentation of most individual charge states in a single experiment, with little interference from other charge states that have overlapping mobilties. For example, although the edges of peaks associated with the +11 to +23 charge states of myoglobin shown in Figure 4, overlap slightly, peak separation is sufficient to extract individual CID/MS information for most of these ions with minimal interference from neighboring charge states [40]. However, this does not hold for lower charge states of myoglobin (e.g., the +8 to +10 states) [52]. In the example shown in Figure 5 for CID/MS analysis of the series of peaks observed at $3.0 \mathrm{~ms}$ (corresponding to activation of the ubiquitin $[\mathrm{M}+7 \mathrm{H}]^{7+}$ precursor) we observe interference from the $[\mathrm{M}+5 \mathrm{H}]^{5+}$ charge state. In this case, the large feature in the CID/MS slice that is observed at an $\mathrm{m} / \mathrm{z}$ value of 1713.0 corresponds to $[\mathrm{M}+5 \mathrm{H}]^{5+}$ ions that have not undergone dissociation. The $[\mathrm{M}+5 \mathrm{H}]^{5+}$ charge state favors relatively compact conformations (even under high-injection voltage conditions) and thus has a mobility that is similar to the extended $[\mathrm{M}+7 \mathrm{H}]^{7+}$ structure [43]. These lower charge states require a higher-field excitation in order to undergo efficient dissociation.

Although this approach is still at an early stage of development, it is apparent that the ability to obtain fragmentation patterns in an on-line approach is a valuable means of complementing assignments that are made from precursor ion charge state distributions. Other groups have recently shown that the information obtained from CID data obtained from different charge states can vary substantially and that it is useful to examine a number of charge states in order to extract detailed information about amino acid sequence across large portions of the protein [21,22]. In favorable cases a single IMS-CID/MS frame may contain fragmentation for many charge states; thus, the approach is suitable for high-throughput characterization.

\section{Nanoflow LC/IMS-MS of larger protein mixtures}

A number of larger protein mixtures have also been studied with the LC/IMS-MS and LC/IMS-CID/MS approach. These include well-defined mixtures of a broad distribution of different types of proteins, ranging from $8 \mathrm{kDa}$ to $80 \mathrm{kDa}$. Overall, the basic strategies used to identify individual features that are observed in datasets for the three component mixture appear to be

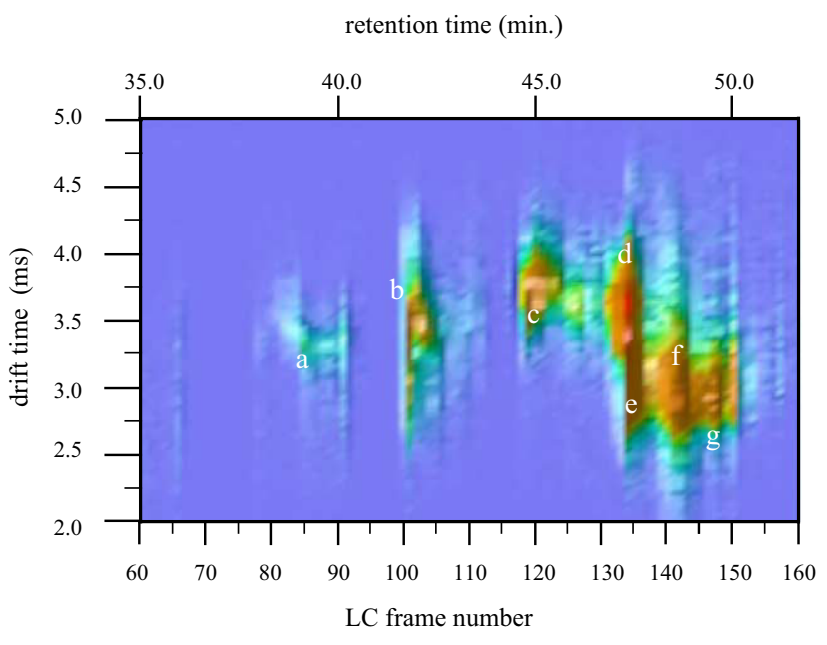

Figure 6. Two-dimensional contour plot of $t_{\mathrm{R}}\left[t_{\mathrm{D}}\right]$ distributions for a six-component protein mixture. The proteins present in the mixture, labeled (a) through (g) (see text for description) as well as $t_{\mathrm{R}}\left[\mathrm{t}_{\mathrm{D}}\left(t_{\mathrm{F}}\right)\right]$ are listed in Table 1 in order of LC elution. The most intense features are listed in red and the least intense features are shown in blue.

useful in assigning peaks in more complex systems. So far we have surveyed a number of different combinations of prepared (commercially available) protein mixtures; the most complex mixture contained ten components. Although we have not attempted to optimize detection limits, good signal-to-noise ratios can be obtained for most of the proteins that we have studied upon injection of $\sim 50$ to 100 fmols.

It is worthwhile to briefly present example data for a larger system. Figure 6 shows a two-dimensional $t_{\mathrm{R}}\left[t_{\mathrm{D}}\right]$ contour plot obtained from nanoflow LC/IMS-MS of a six protein mixture. As described in the experimental section, this mixture was prepared to be an equimolar mixture of ubiquitin, ribonuclease $\mathrm{A}, \alpha$-lactalbumin, hemoglobin, carbonic anhydrase and lactoferrin. In total, $75 \mathrm{ng}$ of the mixture was injected onto the LC column in order to initiate experiments. Ions were injected into the drift tube at the relatively high injection voltage of $136 \mathrm{~V}$ in order to favor the formation of extended gas-phase conformations. These data were obtained while operating the second-field region of the drift tube under low-field conditions and thus the data are dominated by ESI charge state distributions for the intact protein ions.

Overall the appearance of the plot in Figure 6 is very similar to the data that are shown in Figure 3. At distinct retention times the distribution of charge states that are formed by ESI is dispersed according to differences in the gas-phase mobilities of the different ions. In some cases, there are only modest differences in the drift times of different ions. For example, peaks centered at LC frames 85 and 120 (labeled $a$ and $c$, respectively) correspond to distributions of ions that are dispersed by only $\sim 0.5 \mathrm{~ms}$ across the mobility distribu- 
Table 1. Peak positions $t_{\mathrm{R}}\left[t_{\mathrm{D}}\left(t_{\mathrm{F}}\right)\right]$ and protein assignments for peaks in Figure 6 .

\begin{tabular}{|c|c|c|c|c|c|}
\hline $\begin{array}{l}\text { Peak } \\
\text { label }\end{array}$ & $\begin{array}{c}t_{\mathrm{R}} \\
(\min )^{\mathrm{c}}\end{array}$ & $t_{\mathrm{D}}\left(t_{\mathrm{F}}\right)-\mathrm{n}^{\mathrm{d}}$ & $\begin{array}{l}\text { MW } \\
\text { exptl }^{\mathrm{a}}\end{array}$ & $\begin{array}{l}\mathrm{MW} \\
\text { calcd }^{\mathrm{b}}\end{array}$ & $\begin{array}{c}\text { Protein } \\
\text { assignment }\end{array}$ \\
\hline $\mathrm{a}$ & 39.2 & $\begin{array}{l}3.69(34.9)-7 ; 3.44(32.6)-8 ; 2.68(30.8)-9 ; \\
3.26(30.8)-9 ; 3.23(29.2)-10 ; 3.02(27.9)-11\end{array}$ & $13676 \pm 8$ & 13682 & Ribonuclease $A$ \\
\hline b & 41.8 & $\begin{array}{l}\text { 4.00(36.5)-4; 3.48-4.18(32.7)-5; 4.07(29.8)-6; } \\
2.55(27.6)-7 ; 3.73(27.6)-7 ; 2.30-2.85(25.9)-8 ; \\
3.35(25.9)-8 ; 2.68(24.4)-9 ; 3.10(24.4)-9 ; \\
2.93(23.2)-10 ; 2.81(22.1)-11 ; 2.72(21.2)-12 ; \\
2.60(20.3)-13\end{array}$ & $8564 \pm 8$ & 8565 & Ubiquitin \\
\hline c & 45.0 & $\begin{array}{l}3.99(32.2)-46 ; 4.01(31.8)-47 ; 3.93(31.5)-48 ; \\
3.85(31.1)-49 ; 3.89(30.8)-50 ; 3.87(30.5)-51 ; \\
3.83(30.2)-52 ; 3.75(30.0)-53 ; 3.75(29.7)-54 ; \\
3.73(29.4)-55 ; 3.71(29.1)-56 ; 3.64(28.8)-57 ; \\
3.62(28.6)-58 ; 3.58(28.4)-59\end{array}$ & $76153 \pm 73$ & 76144 & Lactoferrin \\
\hline$d$ & 47.3 & $\begin{array}{l}3.39(35.5)-7 ; 4.02(35.5)-7 ; 2.93(33.2)-8 ; \\
3.69(33.2)-8 ; 2.72(31.3)-9 ; 3.48(31.3)-9 ; \\
2.60(29.7)-10 ; 3.35(29.7)-10 ; 2.47(28.4)-11 ; \\
3.18(28.4)-11 ; 2.97(27.2)-12 ; 3.52(27.2)-12\end{array}$ & $14182 \pm 8$ & 14178 & $\alpha$-Lactalbumin \\
\hline e & 47.5 & $\begin{array}{l}4.90(34.2)-8 ; 4.65(32.3)-9 ; 4.53(30.6)-10 ; \\
4.12(29.2)-11 ; 3.87(28.0)-12 ; 3.69(26.9)-13 ; \\
3.50(25.9)-14 ; 3.38(25.0)-15 ; 3.26(24.3)-16 ; \\
3.13(23.5)-17 ; 3.05(22.9)-18 ; 2.99(22.3)-19 ; \\
2.93(21.7)-20 ; 2.84(21.2)-21 ; 2.76(20.7)-22 ; \\
2.68(20.3)-23\end{array}$ & $15052 \pm 4$ & 15053 & $\begin{array}{l}\text { Hemoglobin, } \\
\alpha \text { chain }\end{array}$ \\
\hline$f$ & 48.5 & $\begin{array}{l}4.53(33.6)-16 ; 4.36(32.6)-17 ; 4.24(31.7)-18 ; \\
4.08(30.8)-19 ; 3.99(30.1)-20 ; 3.89(29.4)-21 ; \\
3.79(28.7)-22 ; 3.73(28.1)-23 ; 3.64(27.5)-24 ; \\
3.56(26.9)-25 ; 3.50(26.4)-26 ; 3.44(25.9)-27 ; \\
3.38(25.4)-28 ; 3.26(25.0)-29 ; 3.21(24.6)-30 ; \\
3.21(24.2)-31 ; 3.13(23.8)-32 ; 3.09(23.5)-33 ; \\
2.91(23.1)-34 ; 2.91(22.8)-35 ; 2.85(22.5)-36 ; \\
2.85(22.2)-37 ; 2.82(21.9)-38 ; 2.80(21.6)-39 ; \\
2.76(21.3)-40\end{array}$ & $29013 \pm 19$ & 29023 & $\begin{array}{l}\text { Carbonic } \\
\text { anhydrase }\end{array}$ \\
\hline$g$ & 49.5 & $\begin{array}{l}4.73(33.2)-9 ; 4.40(31.5)-10 ; 4.16(30.1)-11 ; \\
3.87(28.8)-12 ; 3.67(27.7)-13 ; 3.46(26.7)-14 ; \\
3.37(25.8)-15 ; 3.21(25.0)-16 ; 3.13(24.3)-17 ; \\
2.97(23.6)-18 ; 2.93(22.9)-19 ; 2.82(22.4)-20 ; \\
2.76(21.8)-21 ; 2.70(21.3)-22 ; 2.64(20.9)-23 ; \\
2.39(20.4)-24\end{array}$ & $15956 \pm 13$ & 15954 & $\begin{array}{l}\text { Hemoglobin, } \beta \\
\text { chain }\end{array}$ \\
\hline
\end{tabular}

a Values correspond to averaged molecular weights in Da, calculated from experimental $\mathrm{m} / \mathrm{z}$ values for each $n$. Standard deviations are also included. bValues correspond to isotopically averaged molecular weights in Da. The molecular weights for these proteins were taken from Swiss-Prot and TrEMBL databases (www.expasy.ch/).

"Values correspond to the value of the retention time where the largest integrated ion signal is observed.

dValues correspond to the average drift times (in $\mathrm{ms}$ ) and flight times (in $\mu \mathrm{s}$ ) recorded for the centers of different charge states. Flight times are converted to $\mathrm{m} / \mathrm{z}$ values using a simple polynomial calibration to a known system of peaks that are recorded before and after the LC experiment is carried out. The assignments of different charge states for peaks are denoted as $-n$, where $n$ corresponds to the charge state of the ion.

tion. Other features are quite broad. For example, within frames 132 to 135 we observe ions observed over a wide range of drift times (from $\sim 2.3$ to $4.6 \mathrm{~ms}$ ).

In order to assign the features in this plot to specific proteins we have extracted the values of $t_{\mathrm{D}}\left(t_{\mathrm{F}}\right)$ for the peaks that are observed. For example, the analytes that are observed at $t_{\mathrm{R}}=41.8 \mathrm{~min}$ (the feature labeled $b$ in Figure 6) show large distinct peaks at $t_{\mathrm{D}}\left(t_{\mathrm{F}}\right)$ values [in units of $\mathrm{ms}(\mu \mathrm{s})]: 4.00(36.5)$, a broad peak at 3.48(32.7) to 4.18(32.7), 4.07(29.8), 2.55(27.6), 3.73(27.6), a broad peak at $2.30(25.9)$ to $2.85(25.9), \quad 3.35(25.9), \quad 2.68(24.4)$, 3.10(24.4), 2.93(23.2), 2.81(22.1), 2.72(21.2), 2.60(20.3), a broad peak at 2.97 to $3.56(24.7), 2.89(25.5)$, a broad peak at 3.14 to $3.69(25.5), 2.93(26.4), 3.39(26.4), 2.89(27.4)$, 3.52(27.4), 3.08(28.5), 3.65(28.5) and a broad peak at $3.45(29.7)$ to $4.19(29.7)$. From these peaks we are able to establish that more than one analyte has been detected in this region of the dataset. Analysis of the distribution of the most abundant peaks allows us to assign peaks to specific ion charge states. From these we determine a molecular weight of $8564 \pm 8$; this value, combined with the distribution of different drift times that are measured, leads us to assign the abundant series of peaks (within feature $b$ in Figure 6) to the ubiquitin protein. It is also possible to establish the charge states associated with the lower intensity distribution of peaks; from these we derive a molecular weight of $15579 \pm 4$ from this distribution; however, we are not able to unambiguously assign this analyte. Presumably this is a contaminant that is found in one of the commercial protein samples.

A summary of the values that we have obtained from 


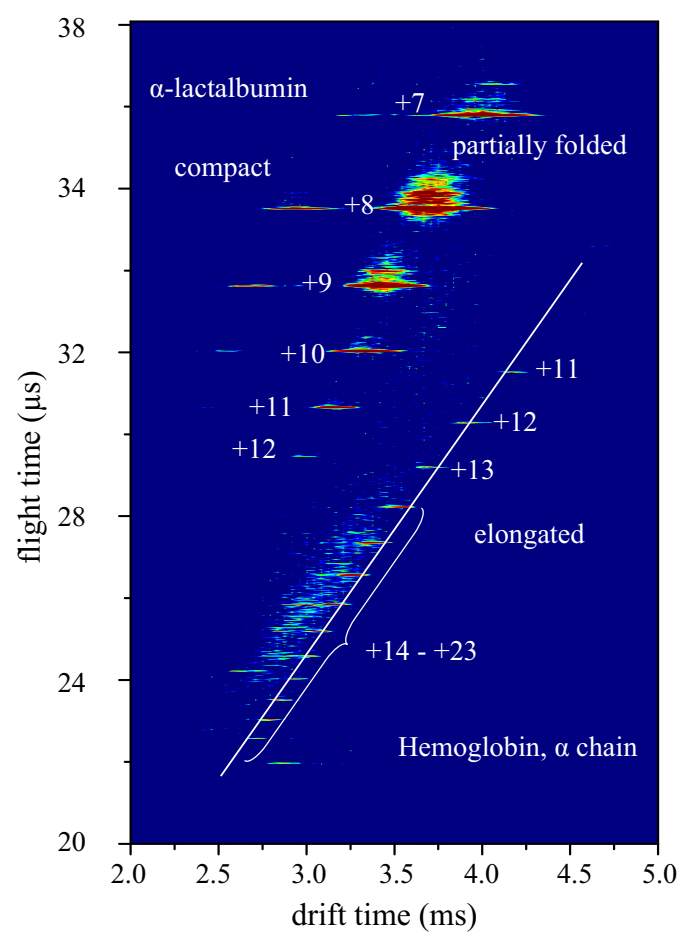

a) Total mass spectrum

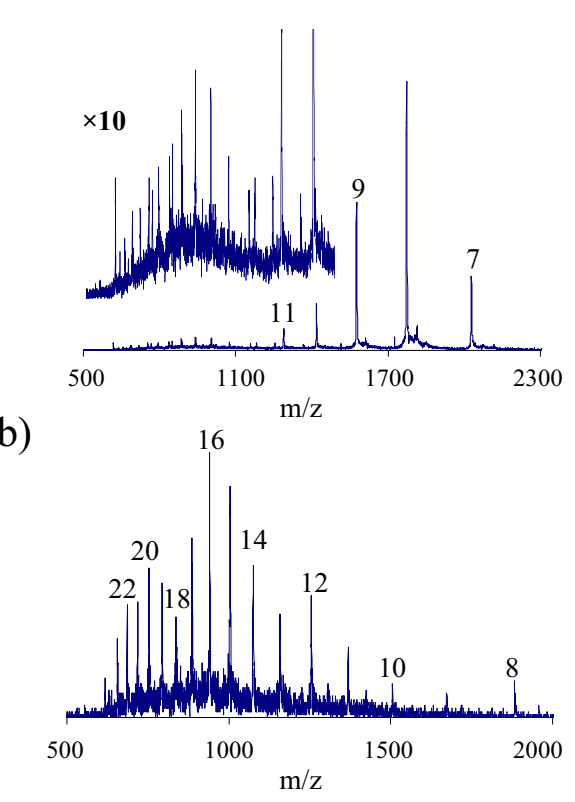

Figure 7. Left: Nested drift(flight) time distributions of coeluting components ( $\alpha$-lactalbumin and hemoglobin, $\alpha$ chain) present at LC frame number $134\left(t_{\mathrm{R}}=47.3 \mathrm{~min}\right)$ in the protein mixture displayed in Figure 6. These data are represented by a false contour plot in which the most intense regions are shown in red. Flight times have been converted to $\mathrm{m} / \mathrm{z}$ values in the spectra to the right. Right: (a) shows a total mass spectrum integrated over the drift range, 2.39 to $4.23 \mathrm{~ms}$. (b) shows a mass spectrum integrated over the $t_{\mathrm{D}}\left(t_{\mathrm{F}}\right)$ range indicated by the solid line in the dataset to the left. This mass spectrum corresponds to the charge state distribution of hemoglobin ( $\alpha$ chain).

most of the large features that are observed in this dataset shown in Figure 6 is given in Table 1. We focus the discussion of this summary on the peaks labeled $a$ through $g$ in Figure 6 because these peaks correspond to components that we expect to be present in the prepared mixture. This summary of information (we use a molecular weight tolerance of $\pm 10 \mathrm{Da}$ for comparison of experimental and calculated values and corroborate assignments by also considering the experimental values of $t_{\mathrm{D}}$ when possible) allows us to assign the features in Figure 6 as: feature $a=$ ribonuclease; $b=$ ubiquitin, $c$ $=$ lactoferrin; $d=\alpha$-lactalbumin; $e=$ the $\alpha$-chain of hemoglobin; $f=$ carbonic anhydrase; and, $g=$ the $\beta$ chain of hemoglobin. In most cases the six proteins in the mixture are well resolved in the LC separation. That is, peak widths across the retention time dimension are normally less than 40 seconds.

Finally, it is instructive to show a single nested $t_{\mathrm{D}}\left(t_{\mathrm{F}}\right)$ frame that is shown in Figure 7. The region we have chosen to examine corresponds to LC frame 134 and is labeled in Figure 6 as peaks $d$ and $e$. The peaks that are observed correspond to $\alpha$-lactalbumin and hemoglobin ( $\alpha$ chain). Several aspects of this frame are noteworthy (and are typical of other datasets that we have obtained but not discussed here). For example, the distribution of peaks that are observed can be grouped into several types of ions. The solid line that is shown falls along a group of peaks that are assigned to the $\alpha$ chain of hemoglobin. At slightly shorter drift(flight) time values, we observe a very low intensity family of peaks having $t_{\mathrm{D}}\left(t_{\mathrm{F}}\right)$ values that fall along a line that spans from $\sim 2.5(24.5)$ to $3.5(28.0)$. The origin of these features is not clear to us at this time, although we suspect that these are associated with another low-level impurity in these samples; however, that they are shifted slightly to lower drift(flight) time values shows one of the advantages of the mobility separation -the ability to remove (or reduce chemical noise). In this case, the low-level features that are observed are largely removed from the series of nearby peaks associated with the $\alpha$ chain of hemoglobin. This is illustrated by comparing the total integrated mass spectrum with the mass spectrum obtained by integrating only along the region of the $\alpha$ chain of hemoglobin peaks.

An additional feature in these data that is interesting is associated with the peaks that are assigned to $\alpha$-lactalbumin. In this case the protein has been injected onto the column in a form in which the disulfide bonds are intact. The peaks that are observed fall along drift(flight) time regions that we normally observe for compact and partially folded gas phase ion states. Note that the hemoglobin chain is found in a region in which highly extended structures are expected. The ability to rapidly resolve partially folded and unfolded states in 
the gas phase may offer unique advantages for protein characterization. For example (as mentioned above), it should be relatively straightforward to calibrate this type of analysis in order to check the disulfide bonding of specific proteins. The measured mobility would provide a means of rapidly determining if disulfide bonding patterns have changed (e.g., due to a variation in the method used to prepare the protein mixtures). In complex systems, disulfide bonding interactions may change without a concomitant change in the total mass of the protein. In this case, the mobility would be used as a means of surveying for the proper folded states in solution. We are currently exploring this possibility in more detail.

\section{Summary and Conclusions}

The development and use of a new nanoflow LC/ IMS-MS (or -CID/MS) approach for the analysis of mixtures of intact proteins has been described. In this approach mixtures of proteins are separated by reversed-phase LC in a capillary column and electrosprayed into the gas phase. The gas-phase ions are then accumulated in a linear trap and periodically are injected into a drift tube, where they are separated based on differences in their gas-phase mobilities. The drift tube incorporates a new split-field design. The first region (which comprises more than $90 \%$ of the total length of the drift region) is operated using relatively low fields; as the mixture of protein ions drifts through this region, different charge states and collision cross sections are separated; upon exiting the low-field region, ions enter a much shorter second field region that can be operated as a focusing element for the intact protein ions, or can be used to collisionally activate precursor ions in order to produce fragments. Upon exiting the drift tube, ions enter the source region of a reflectron geometry TOF mass spectrometer, where they are dispersed by differences in their mass-tocharge ratios and detected. The ability to separate ions in the gas phase in ms timescales provides a means of simplifying regions of the mass spectrum where peaks overlap; additionally, this approach provides a means of characterizing the overall shapes of proteins. At this stage of development the approach is suitable for analysis of small mixtures of proteins, such as those that would be found over narrow regions in 2D-GE separations. We are currently working to improve data acquisition methods, and mass and mobility resolving power to further advance this approach.

\section{Acknowledgements}

This work is supported by a grant from the National Institutes of Health (1R01GM-59145-03). The authors are also grateful for support from the Indiana Genomics Initiative (INGEN), which has funded some instrument development in our group that is related to this work. MHM is supported under the INGEN funds.

\section{References}

1. Aebersold, F.; Goodlett, D. R. Mass Spectrometry in Proteomics. Chem Rev. 2001, 101, 269-295.

2. Gevaert, K.; Vanderkerckhove, J. Protein Identification Methods in Proteomics. Electrophoresis 2000, 21, 1145-1154.

3. Jensen, P. K.; Paša-Tolić, L.; Anderson, G. A.; Horner, J. A.; Lipton, M. S.; Bruce, J. E.; Smith, R. D. Probing Proteomes Using Capillary Isoelectric Focusing-Electrospray Ionization Fourier Transform Ion Cyclotron Resonance Mass Spectrometry. Anal. Chem. 1999, 71, 2076-2084.

4. Kachman, M. T.; Wang, H.; Schwartz, D. R.; Cho, K. R.; Lubman, D. M. A 2-D Liquid Separations/Mass Mapping Method for Interlysate Comparison of Ovarian Cancers. Anal. Chem. 2002, 74, 1779-1791.

5. Tong, W.; Link, A.; Eng, J. K..; Yates, III J. R., Identification of Proteins in Complexes by Solid Phase Microextraction Multistep Elution Capillary Electrophoresis Tandem Mass Spectometry. Anal Chem. 1999, 71, 2270-2278.

6. Peng, J.; Elias, J. E.; Thoreen, C. C.; Licklider, L. J.; Gygi, S. P. Evaluation of Multidimensional Chromatrography Coupled with Tandem Mass Spectometry (LC/LC-MS/MS) for LargeScale Protein Analysis: The Yeast Proteome. J. Proteome Res. 2003, 2, 43-50.

7. Klose, J.; Kobalz, U. 2-Dimensional Electrophoresis of Proteins-an Updated Protocol and Implications for a FunctionalAnalysis of the Genome. Electrophoresis 1995, 16, 1034-1059.

8. Perrot, M.; Sagliocco, F.; Mini, T.; Monribot, C.; Schneider, U.; Shevchenko, A.; Mann, M.; Jeno, P.; Boucherie, H. TwoDimensional Gel Protein Database of Saccharomyces cerevisiae (update 1999). Electrophoresis 1999, 20, 2280-2298.

9. Futcher, B.; Latter, G. I.; Monardo, P.; McLaughlin, C. S.; Garrels, J. I. Sampling of the Yeast Proteome. Mol. Cell. Biol. 1999, 19, 7357-7368.

10. Cash, P. Characterization of Bacterial Proteomes by TwoDimensional Electrophoresis. Anal. Chim. Acta 1998, 372, 121145.

11. Wall, D. B.; Kachman, M. T.; Gong, S. S.; Parus, S. J.; Long, M. W.; Lubman, D. M. Isoelectric Focusing Nonporous Silica Reversed-Phase High-Performance Liquid Chromatography/ Electrospray Ionization Time-of-Flight Mass Spectrometry: a Three Dimensional Liquid-Phase Protein Separation Method as Applied to the Human Erythroleukemia Cell-Line. Rapid Commun. Mass Spectrom. 2001, 15, 1649-1661.

12. Stephenson, Jr.; J. L, McLuckey, S. A.; Reid, G.E.; Wells, J. M.; Bundy, J. L. Ion/Ion Chemistry as a Top-Down Approach for Protein Analysis. Curr. Opin. Biotech. 2002, 13, 57-64.

13. Ge, Y.; Lawhorn, B. G.; ElNaggar, M.; Strauss, E.; Park, J.; Begley, T. P.; McLafferty, F. W. Top Down Characterization of Larger Proteins (45 kDa) by Electron Capture Dissociation Mass Spectrometry. J. Am Chem. Soc. 2002, 124, 672-678.

14. Martinović, S.; Veenstra, T. D.; Anderson, G.A.; Paša-Tolić, L.; Smith, R. D. Selective Incorporation of Isotopically Labeled Amino Acids for Identification of Intact Proteins on a Proteome-Wide Level. J. Mass Spectrom. 2002, 37, 99-107.

15. Loo, R. R.; Cavalcoli, J. D.; VanBogelen, R. A.; Mitchell, C.; Loo, J. A.; Moldover, B.; Andrews, P.C. Virtual 2-D Gel Electrophoresis: Visualization and Analysis of the E. coli Proteome by Mass Spectrometry. Anal. Chem. 2001, 73, 40634070.

16. VerBerkmoes, N. C.; Bundy, J. L.; Hauser, L.; Asano, K.G.; Razumovskaya, J.; Larimer, F.; Hettich, R. L.; Stephenson, J. L. Integrating "Top-Down" and "Bottom-Up" Mass Spectrometric Approaches for Proteomic Analysis of Shewanella oneidensis. J. Proteome Res. 2002, 1, 239-252.

17. Reid, G.E.; Shang, H.; Hogan, J.M.; Lee, G.U.; McLuckey, S.A. Gas-Phase Concentration, Purification, and Identification of 
Whole Proteins from Complex Mixtures. J. Am. Chem. Soc. 2002, 124, 7353-7362.

18. Meng, F.; Cargile, B. J.; Patrie, S. M.; Johnson, J. R.; McLoughlin, S. M.; Kelleher, N. L. Processing Complex Mixtures of Intact Proteins for Direct Analysis by Mass Spectrometry. Anal. Chem. 2002, 74, 2923-2929.

19. Johnson, J. R.; Meng, F.; Forbes, A. J.; Cargile, B. J.; Kelleher, N. L. Fourier-Transform Mass Spectrometry for Automated Fragmentation and Identification of 5-20 kDa Proteins in Mixtures. Electrophoresis 2002, 23, 3217-3223.

20. Håkansson, K.; Cooper, H. J.; Emmett, M. R.; Costello, C.E.; Marshall, A.G.; Nilsson, C. L. Electron Capture Dissociation and Infrared Multiphoton Dissociation MS/MS of an Nglycosylated Tryptic Peptic to Yield Complementary Sequence Information. Anal. Chem. 2001, 73, 4530-4536.

21. Reid, G. E.; Wu, J.; Chrisman, P. A.; Wells, J. M.; McLuckey, S. A. Charge-State Dependent Sequence Analysis of Protonated Ubiquitin Ions via Ion Trap Tandem Mass Spectrometry. Anal. Chem. 2001, 73, 3274-3281.

22. Engel, B. J.; Pang, P.; Reid, G. E.; Wells, J. M.; McLuckey, S. A. Charge State Dependent Fragmentation of Gaseous Protein Ions in a Quadrupole Ion Trap: Bovine ferri-, ferro- and apocytochrome c. Int. J. Mass Spectrom. 2002, 219, 171-187.

23. Bowers, M. T.; Kemper, P. R.; von Helden, G.; van Koppen, P. A. M. Gas-Phase Ion Chromatography: Transition Metal State Selection and Carbon Cluster Formation. Science 1993, $260,1446-1451$

24. von Helden, G.V.; Hsu, M. T.; Gotts, N.; Bowers, M. T. Carbon Cluster Cations with Up to 84 Atoms: Structures, Formation Mechanism, and Reactivity. J. Phys. Chem. 1993, 97, 8182-8192.

25. Clemmer, D.E.; Jarrold, M. F. Ion Mobility Measurements and their Applications to Clusters and Biomolecules. J. Mass Spectrom. 1997, 32, 577-592.

26. Henderson, S. C.; Valentine, S. J.; Counterman, A. E.; Clemmer, D. E. ESI/Ion Trap/Ion Mobility/Time-of-Flight Mass Spectrometry for Rapid and Sensitive Analysis of Biomolecular Mixtures. Anal. Chem. 1999, 71, 291-301.

27. Badman, E. R.; Myung, S.; Clemmer, D. E. Gas-Phase Separation of Proteins and Peptide Ion Fragments Generated by Collision-Induced Dissociation in an Ion Trap. Anal. Chem. 2002, 74, 4889-4894.

28. Myung, S.; Badman, E. R.; Lee, Y. J.; Clemmer, D. E. Structural Transitions of Electrosprayed Ubiquitin Ions Stored in an Ion Trap $\backsim 10 \mathrm{~ms}$ to 30s. J. Phys. Chem. A 2002, 106, 9976-9982.

29. Covey, T.; Douglas, D. J. Collision Cross Sections for Protein Ions. J. Am. Soc. Mass Spectrom. 1993, 4, 616-623.

30. Purves, R. W.; Barnett, D. A.; Ells, B.; Guevremont, R. Elongated Conformers of Charge States +11 to +15 of Bovine Ubiquitin Studied Using ESI-FAIMS-MS. J. Am. Soc. Mass Spectrom. 2001, 12, 894-901.

31. Wu, C.; Siems, W. F.; Asbury, G. R.; Hill, H. H., Jr. Electrospray Ionization High-Resolution Ion Mobility SpectrometryMass Spectrometry. Anal. Chem. 1998, 70, 4929-4938.

32. Gill, A. C.; Jennings, K. R.; Wyttenbach, T.; Bowers, M. T. Conformation of Biopolymers in the Gas Phase: A New Mass Spectrometric Method. Int. J. Mass Spectrom. 2000, 195/196, 685-697.

33. Jarrold, M. F. Peptides and Proteins in the Vapor Phase. Annu. Rev. Phys. Chem. 2000, 51, 179-207.

34. St. Louis, R. H.; Hill, Jr. H. H., Ion Mobility Spectrometry in Analytical-Chemistry. Cr. Rev. Anal. Chem. 1990, 21, 231-355.

35. Wyttenbach, T.; Kemper, P. R.; Bowers, M. T. Design of a New Electrospray Ion Mobility Mass Spectrometer. Int. J. Mass Spectrom. 2001, 212, 13-23.

36. Hoaglund-Hyzer, C. S.; Counterman, A. E.; Clemmer, D. E. Anhydrous Protein Ions. Chem. Rev. 1999, 99, 3037-3079.
37. Hoaglund, C. S.; Valentine, S. J.; Sporleder, C. R.; Reilly, J. P.; Clemmer, D. E. Three-Dimensional Ion Mobility/TOFMS Analysis of Electrosprayed Biomolecules. Anal. Chem. 1998, 70, 2236-2242.

38. Hoaglund-Hyzer, C. S.; Clemmer, D. E. Ion Trap/Ion Mobility/Quadropole/Time-of-Flight Mass Spectrometry for Peptide Mixture Analysis. Anal. Chem. 2001, 73, 177-184.

39. Hoaglund-Hyzer, C. S.; Lee, Y. J.; Counterman, A. E.; Clemmer, D. E. Coupling Ion Mobility Separations, Collisional Activation Techniques, and Multiple Stages of MS for Analysis of Complex Peptide Mixtures. Anal. Chem. 2002, 74, 992 1006.

40. Valentine, S. J.; Koeniger, S. L.; Clemmer, D. E. A Split-Field Drift Tube for Separation and Efficient Fragmentation of Biomolecular Ions. Anal. Chem. 2003, 75, 6202-6208.

41. Lee, Y. J.; Hoaglund-Hyzer, C. S.; Taraszka, J. A.; Zientara, G. A.; Counterman, A. E.; Clemmer, D. E. Collision-Induced Dissociation of Mobility-Separated Ions Using an OrificeSkimmer Cone at the Back of a Drift Tube. Anal. Chem. 2001, 73, 3549-3555.

42. Dahl, D. A. SIMION (Version 7.0). Idaho National Engineering Laboratory, Idaho Falls, ID, USA.

43. Valentine, S. J.; Counterman, A. E.; Clemmer, D. E. Conformer-Dependent Proton-Transfer Reactions of Ubiquitin Ions. J. Am. Soc. Mass Spectrom. 1997, 8, 954-961.

44. Collings, B. A.; Douglas, D. J. Conformation of Gas-Phase Myoglobin Ions. J. Am. Chem. Soc. 1996, 118, 4488-4489.

45. Clemmer, D. E.; Hudgins, R. R.; Jarrold, M. F. Naked Protein Conformations: Cytochrome $c$ in the Gas Phase. J. Am. Chem. Soc. 1995, 117, 10141-10142.

46. Shelimov, K. B.; Jarrold, M. F. "Denaturation" and Refolding of Cytochrome c In Vacuo. J. Am. Chem. Soc. 1996, 118, 10313-10314.

47. Shelimov, K. B.; Clemmer, D. E.; Hudgins, R. R., Jarrold, M. F. Protein Structure In Vacuo: The Gas Phase Conformations of BPTI and Cytochrome c. J. Am. Chem. Soc. 1997, 119, $2240-$ 2248.

48. Woenckhaus, J.; Mao, Y.; Jarrold, M. F. Hydration of Gas Phase Proteins: Folded +5 and Unfolded +7 Charge States of Cytochrome c. J. Phys. Chem. B. 1997, 101, 847-851.

49. Li, J.; Taraszka, J. A.; Counterman, A. E.; Clemmer, D. E. Influence of Solvent Composition and Capillary Temperature on the Conformations of Electrosprayed Ions: Unfolding of Compact Ubiquitin Conformers from Pseudonative and Denatured Solutions. Int. J. Mass Spectrom. 1999, 185/186/187, $37-47$.

50. Mao, Y.; Woenckhaus, J.; Kolafa, J.; Ratner, M. A.; Jarrold, M. F. Thermal Unfolding of Unsolvated Cytochrome $c$ : Experiment and Molecular Dynamics Simulations. J. Am. Chem. Soc. 1999, 121, 2712-2721.

51. Jarrold, M. F.; Honea, E. C. Annealing of Silicon Clusters. J. Am. Chem. Soc. 1992, 114, 459-464.

52. Shelimov, K. B.; Jarrold, M. F. Conformations, Unfolding and Refolding of Apomyoglobin in Vacuum: an Activation Barrier for Gas-Phase Protein Folding. J. Am. Chem. Soc. 1997, 119, 2987-2994.

53. Valentine, S. J.; Clemmer, D. E. H/D Exchange Levels of Shape-Resolved Cytochrome $c$ Conformers in the Gas Phase. J. Am. Chem. Soc. 1997, 119, 3558-3566.

54. Valentine, S. J.; Anderson, J. G.; Ellington, A. E.; Clemmer, D. E. Disulfide-Intact and -Reduced Lysozyme in the Gas Phase: Conformations and Pathways of Folding and Unfolding. J. Phys. Chem. B 1997, 101, 3891-3900.

55. Trubuil, A. Analysis of One-Dimensional Electropherograms. Comput. Appl. Biosci. 1993, 9, 451-458. 